Linguista: Jurnal IImiah Bahasa, Sastra, dan Pembelajarannya

Vol.3, No.1, Juni 2019, hal $50-58$

ISSN (print): 2579-8944; ISSN (online): 2579-9037

Avaliable online at: http://e-journal.unipma.ac.id/index.php/linguista

\title{
Nilai Nasionalisme Dan Moral Dalam Novel Diponegoro Dan Perang Jawa Karya Ms Ardian Gajah Dan Penerapannya Dalam Pembelajaran Bahasa Dan Sastra Indonesia
}

\author{
Yulin Setianingsih \\ SMP Negeri 1 Wonosari Kabupaten Madiun, Indonesia \\ e-mail: yulinsetianingsih12@gmail.com
}

\begin{abstract}
Abstrak
Penelitian ini bertujuan untuk mendeskripsikan nilai nasionalisme dan sikap kepribadian moral yang ada dalam novel Diponegoro dan Perang Jawa: MS Ardian dan penerapannya pada pembelajaran bahasa dan sastra Indonesia. Penelitian ini dilaksanakan selama 6 bulan. Penelitian ini menggunakan pendekatan deskriptif kualitatif. Sumber data berasal dari novel Diponegoro \& Perang Jawa: MS Ardian dan data dari hasil observasi dan wawancara yang berlokasi di SMP NEGERI 1 WONOASRI. Teknik pengumpuan data dalam penelitian ini adalah dokumentasi, observasi, dan wawancara. Teknik analisis data menggunakan dua teknik analisis yaitu content analysis dan metode deskriptif. Content analysis digunakan saat menganalisis data dari novel, sedangkan metode analisis deskriptif digunakan untuk mendeskripsikan data yang diperoleh saat dilapangan. Hasil temuan penelitian diperoleh sebagai berikut: (1) Nilai nasionalisme dalam novel tersebut banyak ditunjukkan dengan sikap rela berkorban untuk membela negara dan menghargai lambang negaranya (2) Semua sikap kebribadian moral terkandung dalam novel tersebut, yakni Sikap kejujuran, kesediaan bertanggung jawab, kemandirian, keberanian, dan sikap kerendahan hati, dan (3) Hasil analisis nilai nasionalisme dan moral digunakan sebagai bahan tugas dalam kelompok. Ketika kedua nilai dari novel tersebut diterapkan, pada awal pembelajaran siswa hanya mengerti pengertiannya, hal itu dikarenakan guru hanya menjelaskan pengertian secara singkat. Kondisi pembelajaran sangat kondusif karena kegiatan siswa terlalu terfokus pada proses pengerjaan tugas. Meskipun tergolong materi yang berat namun pembelajaran tidak membutuhkan fasilitas yang mewah, cukup perangkat pembelajaran yang lengkap.
\end{abstract}

Kata kunci: Nilai Nasionalisme; Moral; Novel; Pembelajaran Bahasa dan Sastra Indonesia

\section{Nationalism and Morality Values on "Novel Diponegoro dan Perang Jawa" by Ms Ardian Gajah and Its Implementation in The Learning of Indonesia Language}

\begin{abstract}
This study aims at describing nationalism and moral values on the novel Diponegoro dan Perang Jawa by MS Ardian Gajah and its implementation in the learning of Indonesian Language. The study was conducted during six months. The study used descriptive qualitative. Data sources were novel Diponegoro dan Perang Jawa by MS Ardian Gajah and the data of observation and interview were taken place in SMP Negeri 1 Wonoasri. The data were collected through documentation, observation, and interview. The data were analyzed by using two kinds of analysis technique, namely content analysis and Miles \& Huberman's descriptive analysis technique. The content
\end{abstract}


analysis was used to analyze the data taken from novel, while Miles \& Huberman's descriptive analysis technique was used to analyze the field data. The findings show that (1) Nationalism values found in the novel is seen from the willingness attitude of having sacrifice to defend one's nation and respect his nation symbol, (2) Some moral values found in the novel are honesty, responsibility, independence, brave, humbleness, and (3) The analysis of nationalism and moral values is used as tasks that are being discussed in the groups. While the two values are applied, the students understand the definition of the values. It happens because the teacher only explains the definition simply. The condition of teaching learning process considers conducive, since the students focus on doing the tasks. Thus, the teaching learning process mostly needs sufficient learning media, but not the expensive one.

Keywords: Nationalism and Morality Values; Novel; Indonesian Language and Literature Learning.

\section{Pendahuluan}

Manusia dianggap sebagai makhluk hidup yang paling sempurna di antara makhluk hidup yang lain. Banyak pihak yang menganggap bahwa manusia lebih banyak diberi kelebihan oleh Tuhan dibanding makhluk lain. Perasaan dan akal adalah dua hal yang tidak dimiliki oleh makhluk hidup lain, tetapi merupakan hal yang dianugerahkan Tuhan kepada manusia.

Rasa cinta kepada bangsa dan memiliki sikap serta perilaku baik merupakan karakter yang wajib dimiliki oleh semua orang, terutama orang Indonesia. Sejarah bangsa Indonesia hingga mampu meraih kemerdekaan seharusnya mampu menumbuhkan rasa menghargai pahlawan dan menumbuhkan rasa nasionalisme atau rasa cinta kepada bangsa. Selain itu, bersikap dan berperilaku baik juga wajib dimiliki oleh warga Indonesia, karena Indonesia merupakan negara penganut paham timur, yakni segala perbuatan harus berlandaskan moral.

Nasionalisme merupakan karakter yang harus dimiliki oleh semua warga Indonesia karena terbukti begitu penting perannya bagi bangsa Indonesia. Mohammad Takdir Ilahi (2012: 15) menyatakan bahwa melalui gerakan nasionalisme, bangsa Indonesia mulai termotivasi untuk terus mengintensifikasikan cita-cita idealnya, yakni menjadikan bangsa Indonesia sebagai bangsa yang utuh.

Warga negara adalah unsur penting bagi bangsa Indonesia. Warga negara harus menjadi manusia yang sebaik mungkin, karena kehidupan, sikap dan perilaku warga suatu negara berhubungan dengan negaranya, terutama kaitannya dengan moral. Menurut Elly M. Setiadi (2005: 161) moral meluputi hidup manusia itu sendiri dan dalam kehidupannya bersama dalam keluarga, masyarakat, bangsa, dan dalam negara serta dunia.

Rasa nasionalisme sudah mulai luntur dalam benak siswa SMP NEGERI 1 Wonoasri. Hal tersebut terlihat saat mereka tidak menjalankan program pemerintah terkait nasionalisme. Siswa tidak melaksanakan kewajiban memasang bendera kecil di seragam. Lunturnya nasionalisme juga dapat dilihat saat siswa melaksanakan upacara bendera masih kurang disiplin dan ramai. Walaupun pihak sekolah sudah mengingat sebelum upacara berlangsung.

Hilangnya moral dalam diri siswa SMP NEGERI 1 Wonoasri juga dapat dilihat dalam berbagai peristiwa. Hilangnya rasa hormat kepada guru adalah salah satu perilaku atau sikap amoral yang terjadi di SMP NEGERI 1 Wonoasri. Sikap moral yang 
tidak dimiliki oleh siswa SMP NEGERI 1 Wonoasri adalah sikap tanggung jawab. Para siswa tidak memiliki rasa tanggung jawab sebagai siswa. Tidak mengerjakan tugas dan membolos adalah tanggung jawab dan kewajiban seorang siswa yang tidak dilaksanakan oleh siswa.

Mendapatkan sesuatu untuk dipelajari dan dianut tidak harus dari kehidupan nyata. Karya sastra juga menawarkan nilai-nilai positif yang akan sangat berguna jika diterapkan pada diri seseorang, meskipun nilai-nilai tersebut tidak secara gamblang diperlihatkan oleh pengarang. Dengan membaca karya sastra maka akan membuat jiwa pembaca menjadi tenang dan membentuk karakter seseorang menjadi lebih baik karena nilai-nilai yang terkandung dalam karya sastra tersebut.

Karya sastra dan kehidupan nyata secara pengertian memang dua hal yang bertolak belakang. Karya sastra identik dengan karangan fiktif, sebaliknya kehidupan nyata adalah realita atau kenyataan. Namun karya sastra dengan kehidupan nyata khususnya kehidupan masyarakat atau sosial adalah dua hal yang saling berhubungan. Banyak dijumpai bahwa karya sastra mengandung cerita yang memang terjadi di dunia nyata, baik itu pengarang mengambil dari kehidupannya sendiri atau dari kisah hidup orang lain. Sapardi Djoko Damono (dalam Rachmat Djoko Pradopo et al, 2003: 157) menyatakan bahwa sastra menampilkan gambaran kehidupan, dan kehidupan itu sendiri adalah kenyataan sosial.

Novel adalah salah satu karya sastra yang digunakan seorang pengarang untuk menyampaikan pikiran, ide, dan isi hati atau perasaannya. Seperti karya-karya sastra lain, selain identik dengan karangan, novel juga menyuguhkan fakta-fakta atau realita kehidupan yang disuguhkan di dalam ceritanya, meskipun tetap ada unsur imajinasi dari pengarang tersebut.

Novel adalah karya sastra yang dapat dijadikan sebagai media belajar. Novel mengandung nilai-nilai atau pelajaran-pelajaran yang dapat diambil oleh pembaca. Nilainilai atau pelajaran yang dapat diambil dari novel tersebut tercipta oleh imajinasi pengarang namun juga terdapat nilai-nilai atau pelajaran yang memang sengaja diambil dari kehidupan nyata. Diharapkan semua itu dapat di adopsi oleh pembaca dari dunia sastra ke dunia nyata.

Novel yang banyak mengandung cerita-cerita yang memiliki unsur realita adalah novel sejarah. Seperti namanya, novel sejarah tidak menceritakan kehidupan pada zaman sekarang, namun cerita dari zaman-zaman lampaulah yang diangkat menjadi cerita berbentuk novel. Meski secara garis besar ceritanya diambil dari kisah nyata masa lampau, seperti karya sastra lain, novel sejarah juga dibumbui dengan imajinasiimajinasi pengarang, karena pengetahuan pengarang tidak mungkin mampu sepenuhnya mengetahui peristiwa yang sudah terjadi sangat lama.

Novel sejarah banyak sekali mengangkat kejadian-kejadian yang penting dimasa lampau. Sosok pahlawan adalah salah satu tema yang populer dalam jenis novel ini. Tokoh-tokoh yang diangkat dalam novel jenis ini adalah tokoh yang memiliki peran penting dimasa lampau. Pengarang ingin pembaca belajar melalui nilai-nilai ataupun sosok dari pahlawan yang dijadikan tokoh-tokoh di dalam novel tersebut dan menerapkan hal yang positif yang diperoleh dari tokoh tersebut ke dalam kehidupan pembaca.

Salah satu novel sejarah yang sangat menarik dibaca karena memiliki gaya penulisan yang sangat puitis meskipun menuliskan kisah sejarah adalah novel 
Diponegoro \& Perang : MS Ardison . Novel Diponegoro \& Perang Jawa: MS Ardison ini adalah salah satu novel sejarah yang mengangkat sosok pahlawan dari masa lampau yakni Seorang Pangeran Diponegoro. Hal yang menarik dalam novel ini adalah banyak terkandungnya nilai nasionalisme dan moral. Nilai nasionalisme dan moral tersebutlah yang mengantarkan Pengeran Diponegoro seorang Pahlawan yang membuat rakyat semula menderita menjadi sejahtera. Nilai nasionalisme dalam novel Diponegoro \& Perang Jawa: MS Ardison begitu menarik karena nilai nasionalisme tersebut ditunjukkan saat negara Indonesia belum ada, dan baru ada berwujud kerajaan.

Nilai moral yang terkandung dalam novel Diponegoro \& Perang Jawa MS: Ardison terasa sangat menarik karena seting cerita yang begitu dominan di dalam lingkungan kerajaan, namun dalam novel tersebut para tokoh menggunakan moral dalam berpolitik. Selain dalam berpolitik moral juga ditunjukkan para petinggi kerajaan dan para rakyat biasa dalam kehidupan sehari-hari dan dalam bersosialisasi. Sikap dan perilaku moral yang diceritakan dalam novel tersebutlah yang jarang dapat ditemui pada zaman sekarang adalah sesuatu yang menarik dalam novel Diponegoro \& Perang Jawa: MS Ardison.

\section{Metode Penelitian}

Salah satu pendekatan penelitian kualitatif yang digunakan dalam analisis ini adalah metode diskriptif, metode tersebut adalah metode yang betujuan untuk membuat diskripsi, maksusnya membuat gambaran faktual dari apa yag di analisis sebagai objeknya (Djajasudarma, 2010 : 9). Dengan demikian metode tidak terlepas dari sistem yang sudah direncanakan untuk tujuan yang sudah direncanakan dan ditentukan.

Berdasarkan judul penelitian ini, maka penelitian ini termasuk dalam kategori penelitian pustaka sebab yang diteliti adalah bahan dokumen berupa acara talk show. Bahan dokumen terbagi menjadi 2 macam yaitu bahan cetak (buku, jurnal, majalah, koran, dan berbagai jenis laporan lainnya) dan non cetak seperti hasil rekaman audio seperti kaset, video, you tobe (Zed, 2008:6).

Penelitian ini juga termasuk penelitian deskriptif kualitatif yang berusaha mengungkapkan suatu masalah atau peristiwa sebagaimana adanya.Hasil penelitian ini ditekankan secara objektif tentang keadaan yang sebenernya pada obyek yang diteliti

\section{Hasil dan Pembahasan}

\section{Nilai nasionalisme yang terdapat dalam Novel Diponegoro \& Perang Jawa: MS Ardison.}

Berdasarkan analisis data dapat dipaparkan bahwa data yang mengandung makna nilai pendidikan nasionalisme dan moral yang terdapat dalam novel Diponegoro \& Perang Jawa: Ms. Ardison.

\section{a. Berkorban Demi Negara}

Masyarakat Indonesia adalah masyarakat yang beranekaragam, oleh karena itu kehidupan individu, bermasyarakat, dan berbangsa selalu didasari pada keanekaragaman dan kepercayaan masing-masing. Sejalan dengan pendapat 
Mohammad Takdir Ilahi (2012: 5) bahwa secara politis kehidupan kenegaraan pun didasai pada nilai-nilai berkorban demi negara pada setiap individu. Atas dasar pertimbangan tersebut, maka nilai-nilai pendidikan nasionalisme dan karakter bangsa harus didasarkan pada nilai-nilai yang berasal dari nasionalisme.

Nilai berkorban demi Negara yang dipaparkan oleh para tokoh-tokoh yang terdapat dalam novel Diponegoro \& Perang Jawa sangat digambarkan oleh tokoh Diponegoro sendiri, yang tak sabar dari kecil menunggu waktu melutusnya pembrontakan keberanian untuk melawan penindasan kala itu rakyat pribumi. Senada Bauer (dalam Andre, 2012: 1) nasionalisme adalah kesatuan perasaan dan perangai yang timbul karena persamaan nasib. Yang digambarkan penindasan yang terjadi berlangsung lama di masyarakat pribumi.

\section{b. Mencintai Lambang Negara}

Nilai mencintai lambing Negara juga tergambar dalam novel Diponegoro \& Peperangan Jawa karya Ms Ardison, dimana pada setiap individu harus mencintai lambing Negara yaitu Bendera Merah Putih dan Burung Garuda dan sebagai landasan dasar Pancasila, mencintai lambing Negara tergambar pada tokoh Diponegoro berserta para rakyat jelata ditandai dengan mereka memasang kain warna merah dan putih sebagai lambing bahwa ia adalah Indonesia kepada belanda pada waktu peperang ditanah jawa. Sejalan dengan pendapat Zubaedi (2012), bahwa mencintai lambing negara dan Negara adalah prilaku yang didasarkan pada upaya yang menjadikan dirinya sebagai orang yang selalu menjunjung tinggi harkat martabat suatu identitas bangsanya.

\section{c. Menjaga Kedaulatan Bangsa}

Berani merupakan salah satu sifat yang ditunjukan untuk menjaga apa yang dimiliki sebagai hak dan menjaga apa yang sebagai kewajibannya. Menjaga kedaultan Negara merupakan tugas pokok bagai seluruh jajaran masyarakat, karena menjaga kedaulatan Negara adalah kewajiban bagi seluruh bangsa Indonesia. Sejalan dengan pendapat Heri Herdiawanto \& Jumanta Hamdayama (2010: 39), bahwa menjaga kedaulatan Negara tidak hanya dilakukan oleh para aparat penegak hukum saja, namun seluruh aspek masyarakat harus saling menjaga kedaulatan Negara karena menjaga kedaultan Negara adalah wajib.

Nilai menjaga keadaulatan Negara ini digambarkan oleh tokoh Pangeran Diponegoro, dimana beliau menolak dengan tegas masuknya budaya belada pada kala itu, karena akan meracuni masyarakat pribumi, penolakan tersebut disampaikan langsung di kraton pada acara gelar temu rakyat, hal tersebut sematamata untuk menghindari perpecahan dimasyarakat karena budaya asing yang dibawa belanda akan akan meracuni setiap elemen masyarakat. Hal ini mencerminkan nilai keadulatan menjaga Negara adalah tugas setiap orangyang dapat di pahami oleh setiap pembaca.

\section{d. Antusiasme Acara Kenegaraan}

Antusiasme acara kenegaraan yang terdapat pada novel Diponegoro \& Peperangan Jawa digambarkan pada seluruh masyarakat pribumi berbondong-bondng datang 
kerumah Diponegoro mengakat senjata untuk melawan Belanda kala itu karena inseden pencabutan patok batas wiliyah yang dilakukan oleh Belanda. Masyarakat digerakan untuk andil serta dalam hal ini karena masyarakat memiliki hak yang sama untuk mengikuti acara tersebut yaitu mengusir Belanda dari kawasan pribumi. Upaya mereka para pribumi dan Diponegoro membuahkan hasil diacara kenegaraan yang membekukan hati Belanda. Walaupun hambatan yang terjadi dalam novel Diponegoro \& Peperangan Jawa ini cukup banyak, tetapi mereka tetap berusaha dan berupaya menjalankan tugas dan kewajiban yang tetap harus dijalani oleh mereka para pribumi untuk menjaga Indonesia dari Belanda.

\section{Sikap-Sikap Kepribadian Moral yang Terdapat dalam Novel Diponegoro \& Perang Jawa: MS Ardison.}

Sikap kepribadian moral yang terdapat pada novel Diponegoro \& Perang Jawa tergambar jelas pada cerita dan ntokoh yang digambarkan pada novel tersebut. Ada 6 sikap kepribadian moral yang di gambarkan pada novel Diponegora \& Peperangan Jawa, yaitu:

\section{a. Kejujuran}

Nilai sikap kejujuran ditunjukan pada novel Diponegoro \& Peperangan Jawa tokoh Diponegoro kala menjabat sebgai kepala administrasi bidang pertanahan di Kraton Jogja, dengan hati- hati memegang amanah menjaga keungan dan menjaga kebenaran arsip-arsip tanah milik rakyat. Hal ini menunjukan bagaimana niklai kejujuran sangat dipentingkan dalam setiap diri msyarakat karena sikap kejujuran merupakan jati diri seseorang, hal ini sedanda dengan yang disampaikan Kohn (dalam H.A.R Tilaar, 2007: 24) menyatakan pendapatnya bahwa rasa nasionalime harus dimiliki setiap manusia yang didasri kejujuran pada diri sendiri dan kejujuran pada bamngsanya, karena kejujuran merupakan inti dari hidup manusia.

Hal ini tergambar jelas nilai sikap kejujuran pada novel Diponegoro \& Peperangan Jawa yang bisa diambil langsung oleh pembaca dampak positifnya.

\section{b. Kesedian Bertanggung Jawab}

Sikap kesidian bertanggung jawab digambarkan pada tokoh Diponegoro diaman pada saat itu Diponegoro menjadi komandsa dalam melawan Belanda, Diponegoro tidak lupa member asupan makanan padapara prajuritnya ditengahtengah suasana yang genting dan menuju perperangan, beliau tetapa memikirkan prajurit yang dibawanya karena pertanggung jawaban terhadap Negara dan keluarga prajurit yang ditinggalakan. Nilai sikap kesedian bertanggung jawab sangat kental digambarkan pada novel Diponegoro \& Peperangan Jawa, pada masa itu.

Kededian bertanggung jawab sejalan dengan apa yang disampaikan oleh H.A.R Tilaar (2007: 24) mengungkapkan bahwa bertanggung jawab adalah sikap yang harus dimiliki oleh setiap manusia dan sikap yang menjadi dasar dari seorang pemimpin, karena dengan bertanggung jawab maka akan tercemin kepemimpinan yang adil. Hal ini sesuai dengan sikap kesedian bertanggung jawab pada novel Diponegoro \& Peperangan Jawa yang digambarkan oleh toko Diponegoro sendiri.

\section{c. Kemandirian}

Sikap kemandian juga di tunjukan oleh Diponegoro ketika mempimpin perang dan menyebut perang tersebut adalah Jihat Bilsabillah, dimana tentara Belanda juga mengakui akan kemandirian dari Diponegoro kala itu memimpin 
perlawanan pada novel Diponegoro \& Peperangan Jawa. Hal ini sejalan dengan apa yang dimaksudkan dari tujuan sikap moral dari seseorang, salah satunya adalah sikap kemandian sesuai dengan Andre (2013: 1-2) sikap moral kemandirian bukan hanya suatu perjuangan kemerdekaan untuk melepaskan diri dari belenggu penjajahan, tetapi memiliki tujuan yang lebih mendalam, sehingga kemandirian itu dimiliki oleh semua orang.

Dari paparan gambaran data tentang kemandirian Diponegoro sejalan dengan yang diungkapankan oleh Andre (2013: 12)

\section{d. Keberanian}

Keberanian adalah sikap moral yang dimiliki Diponegoro dalam novel Diponegoro \& Perang Jawa, gambaran sikap keberanian Diponegoro sudah digambarkan sedari kecil, diman Diponegoro adalah sosok pemuda dan orang yang berani melantangkan perang ke Belanda ketika belanda mulai bertindak mematok tanah-tanah pribumi di daerah Jogja, tanpa getar keberanian itu ditunjukan oleh Diponegoro dalam membela tanah airnya, moral dan sikap nasionalisme sejalan dengan apa yang di ungkapakan oleh pendapat Andre (2013: 1-2) nasionalisme bukan hanya suatu perjuangan kemerdekaan untuk melepaskan diri dari belenggu penjajahan, tetapi memiliki tujuan yang lebih mendalam, sehingga nasionalisme itu memiliki kaitan erat dengan sikap dan moral serta keberanian dari bangsa untuk melepaskan diri dari sebuah belenggu kepenjajahan.

\section{e. Kerendahan Hati}

Sikap kerendahan hati juga di tunjukan oleh Diponegoro pada novel Diponegoro \& Perang Jawa. Sikap tersebut tergambar pada data yang menyebutkan, dibalik kejayaan dan keberhasilannya Diponegoro tidak mau disebut dialah Pahlawan yang menyelamatkan pribumi, melaikan dia adalah orang biasa yang hanya seorang yang sama seperti pribumi, Indonesia bisa lepas dari Belanda bukanlah kerena dia melaikan semua karena kerja keras dari masyarakat sendiri yang berani dan memperjuangkan haknya. Diponegoro juga sedari kecil lebih suka bergaul dengan para petani, buruh tani dan orang-orang jelata ketimbang ia harus bergaul dengan orang-orang kraton, karena menurut dia di istana adalah tempat persekonkolan, politik dan saling menjatuhkan, dia lebih suka hidup dan bergaul dengan para petani yang member dia arti dari sebuah kejujuran yang sebenarnya, yang sesuai dengan sikap yang ditunjukan kerendahan hatinya. Sejalan denagn apa yang diungkapan oleh Andre (2013: 1-2) bahwa seorang pemimpin yang benarbenar pemimpin adalah orang yang mau berbaur pada orang yang pantas di perjuangkan haknya, dan dia yang memiliki kerendahan hati serta moral yang yang baik untuk menjadi sebuah panutan dalam kepemimpinannya.

\section{Sumbangan Hasil Penelitian sebagai Materi Pembelajaran Sastra Indonesia Di Sekolah}

Menurut peneliti sumbangan hasil penelitian yang telah ditemukan maka dapat dijadikan bahan ajar bagi guru disekolah dalam penanaman nilai sikap nasionalisme dan moral pada anak didik. Pembahasan mengenai hasil penelitian tersebut akan disumbangkan pada guru untuk dijadikan bahan materi pembelajaran Sastra Indonesia. Hasil temuan penelitian tersebut dibahas pada teori yang berkaitan dengan pembelajaran Bahasa dan Sastra Indonesia. Dengan tujuan agar guru dapat menanamkan niali-nilai sikap Nasionalisme dan sikap Moral pendidikan karakter

Linguista Vol. 3, No. 1, Juni 2019: $50-58$ 
tersebut pada siswa dalam proses belajar mengajar. Sejalan dengan pendapat Suharto (2013:16) yang menyatakan bahwa belajar adalah usaha memperoleh pengetahuan atau ketrampilan yang hasilnya adalah perubahan prilaku relative permanent, dan merupakan hasil dari pelatihan yang mendapat penguatan. Jadi dapat disimpulakan bahwa proses belajar mengajar harus mendapatkan sebuah hasil dan perubahan yang mengarah ke hal positif.

Maka Pembelajaran sastra Indonesia juga memperkenalkan nilai-nilai yang terkandung dalam karya sastra seperti yang terdapat dalam novel Diponegoro \& Peperangan Jawa : Karya Ms. Ardison ini dan mengajak siswa untuk ikut menghayati pengalaman-pengalaman yang disajikan dalam karya sastra. Sejalan dengan pendapat Abidin (2012:212), berpendapat bahwa pembelajaran sastra atau pembelajaran apresiasi sastra adalah serangkaian aktivitas yang dilakukan siswa untuk menemukan makna dan pengetahuan yang terkandung dalam karya sastra di bawah bimbingan, arahan, dan motivasi guru melalui kegiatan mengenalkan karya sastra tersebut secara langsung yang telah didukung dengan media yang ada.

Kaitan sikap Nasionalisme dan Moral dengan sastra khususnya dalam novel Diponegoro \& Peperangan Jawa dan sumbangannya dalam pembelajaran sastra Indonesia ini sangat saling berkaitan. Tampak pada nilai-nilai sikap nasionalisme yang disampaikan dalam novel Diponegoro \& Peperangan Jawa : Ms. Ardison. Sikap Nasionalime dan Moral yang terdapat dalam novel tersebut bisa dikembangkan untuk pembentukan karakter bangsa, seperti halnya yang sering digunakan dalam Kompetensi Inti dan Kompetensi Dasar (KD) yang ada dalam materi pembelajaran. Setiap tokoh dalam novel Diponegoro \& Peperangan Jawa : Ms. Ardison menyampaikan nilai-nilai sikap Nasionalisme tersendiri. Guru sebagai pendidik juga mampu menyampaikan niali sikap nasionalisme dan moral tersebut agar lebih mudah dicerna oleh siswa. Sejalan dengan pendapat Dewi (2014), bawha karya sastra mampu menggambarkan kehidupan masyarakat pada zamannya. Cerita yang disajikan dalam karya sastra seperti novel tidak hanya mengandung realita dan nilai pendidikan karakter. Novel juga bisa menggambarkan sebuah perjuangan atau nilai positif lainnya.

Media novel Diponegoro \& Peperangan Jawa : Ms Ardison diharapkan dapat membuat siswa lebih tertarik dalam proses belajar mengajar. Guru juga diharapkan dapat memasukkan penanaman sikap nasionalisme dan moral karakter kepada siswa dalam proses belajar mengajar dengan media novel tersebut. Agar kelak anak didik bangsa Indonesia memiliki nilai-nilai pendidikan dan sikap nasionalisme serta moral yang baik seperti yang di gambarkan Diponegoro yang positif dikalangan masyarakat. Dalam kegiatan pembelajaran guru harus dapat mencoba menciptakan kegiatan yang kooperatif dan kolaboratif, sehingga membuat peserta didik aktif dan mengedapankan kebersamaan yang dapat dijadikan sebagai pembelajaran yang baik.

\section{Kesimpulan}

Bentuk Nilai Nasionalisme dalam Novel Diponegoro \& Perang Jawa: MS Ardison terdiri dari (1) Berkorban demi Negara, (2) Menghargai Lambang Negara, (3) Menjaga Kedaulatan Negara, (4) Antusias Acara Kenegaraan. Adapun sikap-sikap Kepribadian Moral dalam Novel Diponegoro \& Perang Jawa: MS Ardison meliputi (1) Kejujuran, (2) Kesediaan Bertanggung Jawab, (3) Kemandirian, (4) Keberanian, (5) Kerendahan Hati. Secara teoritis penelitian ini diharapkan memiliki nilai guna bagi pembelajaran sastra. Secara lebih khusus diharapkan mampu menambah wawasan dalam kajian strukturalisme sastra. Hasil penelitian ini dan teori-teori dalam tesis ini dapat dijadikan sebagai bahan pembelajaran, referensi atau acuan tentang sastra, nasionalisme, moral, dan novel. Secara praktis penelitian ini diharapkan memiliki nilai guna bagi pembaca dan guru. Bagi pembaca, penelitian ini diharapkan mampu membuka pandangan pembaca bahwa novel tidak hanya berbicara tentang cinta, namun juga terdapat novel yang mengandung nilai-nilai yang baik jika diterapkan dalam kehidupan sehari-hari. Bagi guru, 
penelitian ini diharapkan mampu memberi solusi dalam mengatasi masalah-masalah karakter yang dialami oleh para siswa terutama tentang nasionalisme dan moral.

\section{Daftar Pustaka}

Andre.

2012.

Lahirnya

Nasionalisme

Indonesia. http://xcacingpanasx.blogspot.com/2012/11/lahirnya-nasionalismeindonesia.html. Di unduh 10 September 2014.

Ardison, M.S. (2017). Diponegoro \& Perang Jawa. Jakarta Ecosystem Publishing.

Burhan, N. (2012). Teori Pengkajian Fiksi. Yogyakarta: PT. Gadjah Mada University Press.

Setiadi, E. M. (2005). Panduan Kuliah Pendidikan Pancasila untuk Perguruan Tinggi. Jakarta: PT. Gramedia Pustaka Utama.

Elly M. Setiadi, Kama A. Hakam, Ridwan Effendi. 2007. Ilmu Sosial dan Budaya Dasar. Jakarta: Kencana Prenada Media Group.

Emzir. 2011. Metode Penelitian Kualitatif: Analisis Data. Jakarta: PT RajaGrafindo.

Franz Magnis dan Suseno. 1987. Etika Dasar. Yogyakarta: Kanisius.

Heri Herdiawanto dan Jumanta Hamdayama. 2010. Cerdas, Kritis, dan Aktif Berwarganegara. Jakarta: Erlangga.

Herman J. Waluyo. 2002. Pengkajian Sastra Rekaan. Salatiga: Widya Sari Press.

Hesti Mutiara. 2013. Jenis-Jenis Novel. http://hestiimanti.blogspot.com/2013/02/jenis-jenis-novel.html. Diunduh 22 Februari 2015.

Ilahi, M. Takdir. (2012). Nasionalisme dalam Bingkai Pluralitas Bangsa. Jogjakarta: ArRuzz Media.

Malin, B. (2013). Unsur Ekstrinsik Cerita. http://bahasaindonesiayh.blogspot.com/2012/04/unsur-ekstrinsik-ceritacerpennovel.html. Di unduh 22 Februari 2015.

Moleong, L. (2012). Metodologi Penelitian Kualitatif. Bandung: PT. Remaja Rosdakarya.

Stanton, R. (2007). Teori Fiksi. Yogyakarta: Pustaka Pelajar.

Salam, B. (1997). Etika Sosial. Jakarta: PT. Rineka Cipta.

Sugiyono. (2014). Memahami Penelitian Kualitatif. Bandung: Alfabeta.

Sutopo, H. B, (2002). Metode Penelitian Kualitatif. Surakarta: Sebelas Maret University Press.

Suharto, V. T. (2013). Pengantar Teori Belajar-Pembelajaran Bahasa dan Sastra Berbasis Pengalaman. Salatiga: Widya Sari Press.

Wibowo, A. (2013). Pendidikan Karakter Berbasis Sastra. Yogjakarta: Pustaka Pelajar.

Wicaksana, M F. (2012). Pendidikan Nilai-Nilai Moral Melalui Pengajaran Sastra Berbentuk Komik Multimedia Berbasis Flash dengan Mengadaptasikan Kearifan Budaya Lokal. Widyabastra, 1 (1): 38-43. 